\title{
Parametric Analysis for Minimizing the Edge Waves in the Roll Forming
}

\section{Yonghui Park $^{1,2^{*}}$, Changwoo Lee ${ }^{1,2}$, Jinyul Kim ${ }^{1,2}$, Dongwook Kim ${ }^{1,2}$, Hyunjun Ahn ${ }^{1,2}$ and Woonbong Hwang ${ }^{2}$}

\author{
${ }^{1}$ Pohang Institute of Metal Industry Advancement, 56, Jigok-ro, Namgu, Pohang, Korea \\ *Email: yonghuipark@ pomia.or.kr \\ Phone: +82-54-279-9455, Fax: +82-54-279-9419 \\ ${ }^{2}$ Department of Mechanical Engineering, POSTECH, 77, Cheongam-ro, Namgu, \\ Pohang, Korea
}

\begin{abstract}
To identify the cause of edge waves and to minimize them, which are frequently occurring on the steel pipe manufacturing site, the shape of the edge part of skelp has been confirmed according to a design variable and operating condition. In particular, parametric studies were carried out on the variation in the thickness of skelp, $t_{\text {skelp }}$, the roll gap between upper and bottom rolls, $t_{\text {roll }}$, at the forming stage 1, Forming 1, the roll shape, $t_{\text {offset }}$, of the Forming 1, and the material property of skelp to study the generation of edge waves, because these parameters have been determined by field engineers extemporaneously without any physical estimation. For this purpose, the roll design and operating conditions used in the field were applied to the finite element analysis model, and the distribution of contact force between the rolls and skelp, and the distribution of effective plastic strain on the skelp were investigated. The fact that adjusting to $t_{\text {skelp }}$ and $t_{\text {roll }}$ arbitrarily without changing to the roll shape can cause not only the edge waves but also the center waves, was carried out. Especially, the edge waves were reduced without the irregular contact pressure by changing the surface of the upper roll that is offset by target $t_{\text {skelp }}$ in the normal direction of the surface of the bottom roll in the Forming 1, when the target thickness is $t_{\text {skelp }}$. Moreover, there is no significant difference in the vertical load applied to the rolls when high-strength steels are used or when lowstrength steels are used, it is necessary to predict the local maximum and minimum of contact pressure between the skelp and rolls and the shape of the upper roll of the Forming 1 should be modified to decrease irregular contact pressure instead of any design modifications.
\end{abstract}

Keywords: Roll forming; roll design; contact pressure; API 5L; finite element analysis.

\section{INTRODUCTION}

Roll forming technology has developed with the automobile industry to supply light thin-walled steel structures including steel pipes. To produce the thin-walled parts continuously, the conventional method required huge equipment and the size of the parts were limited to the equipment. These two problems strongly lead to the creation of the roll forming process to save time and cost. Its first equipment was developed by Yoder [1] in 1910 in the USA. This technology has several advantages compared to the conventional method such as press, but Galakahar et al. [2] insisted that it is necessary to quantify the operating condition due to complicated contact and dynamic phenomena taking place during the roll forming process. About the history of the rolling forming 
process, all kind of technologies were relied on empirical knowledge based on the experience until the 1970s due to lack of experimental and theoretical studies. However, the scientific approach to the roll forming process analysis has been started with developing computer technology. The use of computers allowed numerical analysis to take into account the influence of the contact conditions on the roll forming process and allowed CAD/CAE/CAM technologies to design equipment and lines efficiently by Kato et al. and others [3-12].

Despite a long history of previous research, it is hard to operate the roll forming process exquisitely in case of pipe makers that import all kind of equipment from world leading companies around Japan and the USA. In other words, all of the equipment are black boxes, and they just manipulate the controller to produce their own product depending on their experiences. Therefore, engineers in newly rising steel pipe makers cannot approach the process strategically in the field due to the complicated relationship between design variable and operation condition, when they try to develop new product or method. To strengthen their competitiveness, it is necessary to focus their problem and to suggest the next step. In the field, the tolerances, spring-back, tearing and edge waves have been considered as critical parameters to minimize them by Wang [13]. By Kim et al. and others [14-19], most previous research has been conducted to investigate the critical parameters by using the finite element analysis, but they are limited in specific conditions and steel pipe makers have not had any interest in the research activity.

To enhance the competitiveness of steel pipe makers, they have maintained one of the optimal methods by changing the operating conditions and the material property of skelp, and have adhered to investing new facility on their line partially to minimize the failure of new applications. For this activity, empiricism and heuristic rules are the best way to improve in the field. When the application succeeds, they select the new method as their standard to produce a new kind of steel pipe without any modification, and the aged rolls are just purchased and replaced by the manufacturer of the roll after a certain period. The problem is that the roll design is not troubled by themselves, but depends entirely on the manufacturer of the roll. Therefore, it is hard to develop a new product and to secure the quality properly without improving the difficulties regarding the roll in the field. Considering the recent tendency of the manufacturing industry that design analysis is included in the engineering process to draw an initial design that is optimized, the steel pipe industry only creates temporary profit and does not ensure the long-term technological competitiveness. Fortunately, there is a worldwide demand for automobile, plant, and general piping as well as for energy mining and transport pipelines in the steel market report by OECD [20], so it will be a good chance to access to new markets.

In this paper, the edge waves were investigated according to the design and operating condition of the forming rolls. Especially, the fact that whether thinner pipe can be produced when the roll position or the roll design is only changed partially was examined based on the previous paper regarding the cause of the edge waves. The structure of the roll design was confirmed by using a CAD program, and the reasons for using the structure were examined through a two-dimensional plane model regarding the contact pressure among the upper and bottom rolls of the forming stage 1, Forming 1, and skelp. Additionally, a three-dimensional model of the roll forming process for API 5L X52 was investigated by parametric analysis regarding the roll gap, the roll shape, and the material property of skelp. By synthesizing the results, new design and operating condition of the Forming 1 were suggested to produce a thinner and strength 
pipe product without the edge waves instead of changing all rolls of the forming and finpass stages.

\section{PRELIMINARY STUDY ON FORMING ROLL}

\section{Roll Design and Contact Analysis Model}

Local edge waves in the roll forming process have been investigated by comparing longitudinal strain according to the fold angle by Tehrani et al. [21-22]. The fold angle should be kept below a particular limit because compressive deformation causes the occurrence of the edge waves. This analysis is necessary to determine the design and operating condition of the forming rolls, but the fold angle is not the cause of compressive deformation on the edge region for all kinds of the roll forming process. There are lots of unknown variables in the roll forming, especially the fold angle is out of engineering area of interest in our problem because the forming rolls were imported, and the edge waves do not happen unless the thickness of the skelp and roll gap are not changed in the field. In other words, this problem needs to find out another cause instead of the fold angle. To examine the configuration of the upper and bottom rolls of the Forming 1, Figure 1 shows a two-dimensional cross-sectional model of the upper and bottom rolls abutting the skelp. The model is symmetric about $\mathrm{x}$-axis with respect to the left endpoint and consists of tangents of several arcs having different radii. If we look only at the arc except for the straight section, the upper roll constitutes four arcs and the bottom roll constitutes three arcs. The upper and bottom rolls were defined as rigid bodies and the skelp was applied as an elastic-plastic behaviour model. Especially, the machine behaviour such as backlash and stiffness were not concerned.
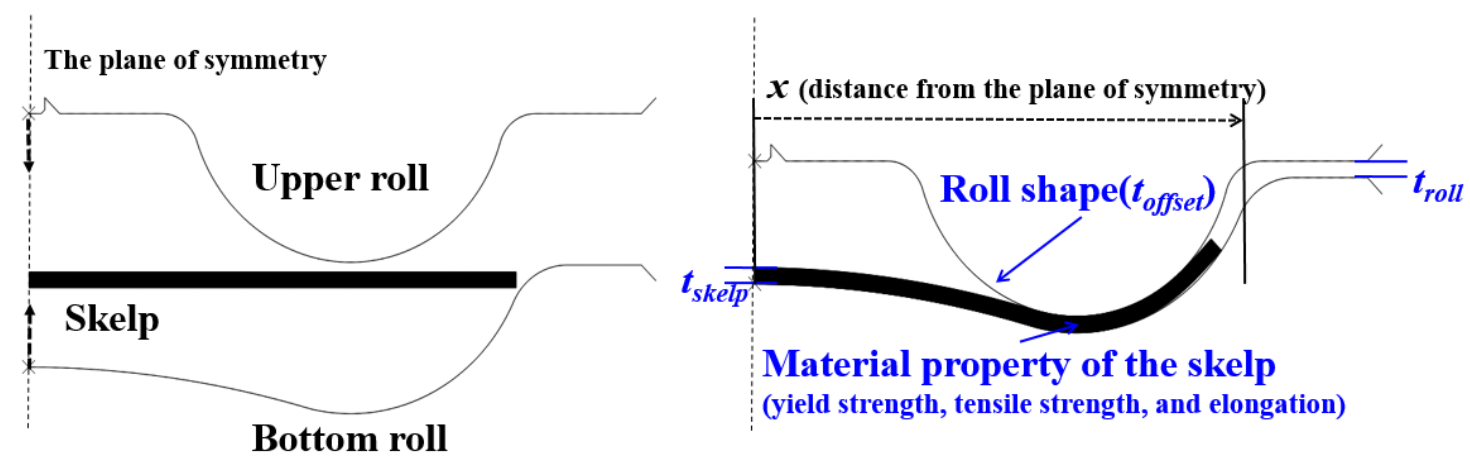

Figure 1. A two-dimensional model of Forming 1.

For the finite element model of the skelp, an 8-node biquadratic plane strain quadrilateral element was selected, and the element that has a geometric deviation factor greater than 0.2 was not found. This model uses the plane strain that is similar to the rolling process from the previous work by Nepershin [23]. In the rolling process, principal strain about the width of the plate is negligible compared to other principal strains about the length and thickness of the plate. In the roll forming process, principal strains about the length and thickness of skelp are negligible compared to the width of skelp. Especially, plain strain about the length of skelp can be assumed zero, because skelp does not become thinner, but become bend through the forming stages. In addition, the previous model by Tehrani et al. [21-22] used the shell element with five integration 
points through the thickness and focused on the longitudinal strain on the edge part, so the distribution of contact force between the rolls and the skelp should be studied to find out another reason for this problem. About the contact formulation between the rolls and skelp, the penalty friction formulation with friction coefficient 0.12 for the tangential behavior and the hard contact for the normal behavior were used. Lastly, ABAQUS static general solver was used to acquire the contact pressure and stress.

If the contact between the rolls and skelp is unstable, a manufacturing defect such as the edge waves will occur. The edge waves are frequently occurring by reducing the thickness of the skelp, $t_{s k e l p}$, and the roll gap, $t_{\text {roll }}$, arbitrarily to produce a pipe that is thinner than the minimum value of $t_{s k e l p}$ from the guideline of the roll. To solve this problem, it is necessary to determine the surface of the other roll on the basis of one roll. For example, it is possible to reduce the unstable contact phenomenon by using the upper roll offset by the target $t_{\text {skelp }}$ that is $t_{\text {offset }}$ in the normal direction of the surface of the bottom roll of Forming 1 (Figure 2). After understanding the basic physical phenomena occurring in the roll design, it is necessary to carry out the parametric analysis of the roll forming process. In the next section, the change of the contact state of the rolls and skelp according to the roll shape and the material property of the skelp was analyzed. Even though $t_{\text {skelp }}$ and $t_{\text {roll }}$ are always changed simultaneously in this paper, the engineer always needs to doubt that these parameters are not the same due to deterioration, misalignment, and so on.

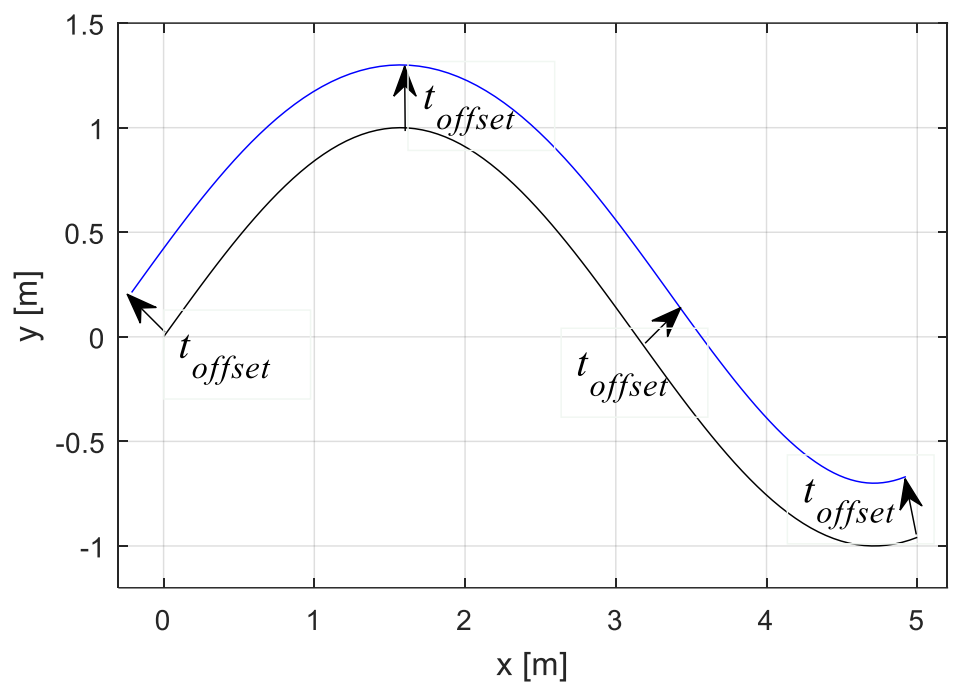

Figure 2. Upper roll offset $t_{\text {offset }}$ on the surface of bottom roll of Forming 1.

\section{Contact Phenomenon According to the Roll Shape}

A two-dimensional contact analysis between the rolls and skelp was performed when the upper roll shape offset as $t_{\text {offset }}$ from the bottom roll shape, the thickness of the skelp, $t_{\text {skelp}}$, and the roll gap, $t_{\text {roll }}$, are changed (Figure 1). When these variables are not designed organically in the field, non-homogenous deformation and stress concentration of the skelp take place regardless of the shape of the rolls (Figure 3). 


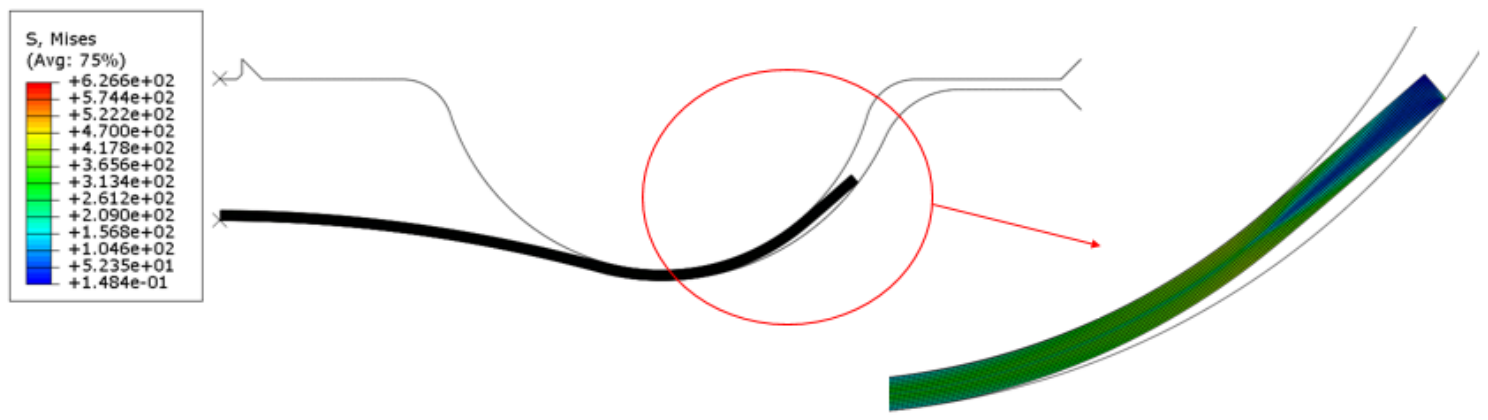

Figure 3. Deformation of skelp.

This phenomenon was investigated in the previous work, so we need to conduct a parametric analysis of the roll forming process to study the trend of the edge waves. $t_{\text {skelp }}$ and $t_{\text {roll }}$ were changed equally, and the contact force distribution of the upper and the bottom surface of the skelp near the upper and bottom rolls was examined by placing the skelp among the rolls according to $t_{\text {skelp }}, t_{\text {roll }}, t_{\text {offset }}$, and the material property. If the skelp was defined as an elastic body, the contact force applied to the skelp is concentrated on specific regions that have the large curvature so that the stress relaxation is not effectively displayed as in Figure 4(a) and 4(b). The pure-elastic material is meaningless in the current roll forming process because mild steel has been selected to the skelp and the steel pipes have got high strength by the post-processing such as the heat treatment. However, this stress concentration should be considered to design the roll and the fold angle, as high strength material such as GIGA steel has been developed and applied to the roll forming process to make strong-light pipes.

To apply a true stress-true strain curve based on the yield strength and tensile strength provided by the API 5L property, to the ABAQUS model, a calculation code, including the Ramberg-Osgood equation was applied to draw the curve. This method has been improved by Kim et al. and others [24-27] to estimate material property exactly. Equation (1) and (2) define elastic and plastic stress-strain behavior respectively in the Ramberg-Osgood equation while the total strain is defined through the sum of elastic strain and plastic strain as in Eq. (3). To define the strength coefficient, $H$, and the strain hardening exponent, $n$, the yield strength and ultimate stress, and strains in Table 1, were substituted to Eq. (3), and the Ramberg-Osgood equations were derived as in Eq. (4) and (5) [24]. About the code deriving the curve, the yield strength $\sigma_{y}$, the tensile strength $\sigma_{u}$, and the elongation $\varepsilon_{f}$ from the API 5L specification, were referred to define the coefficients, and $\varepsilon$ is defined as equal-interval matrix data from 0 to $\varepsilon_{f}$. For example, if the number of $\varepsilon$ is eighty, eighty Eq. (4) were derived. By calculating implicit functions whose $\sigma$ are unknown and aligning the $\sigma$ corresponding to each $\varepsilon$, we can obtain the true stress and strain required for the ABAQUS input. 


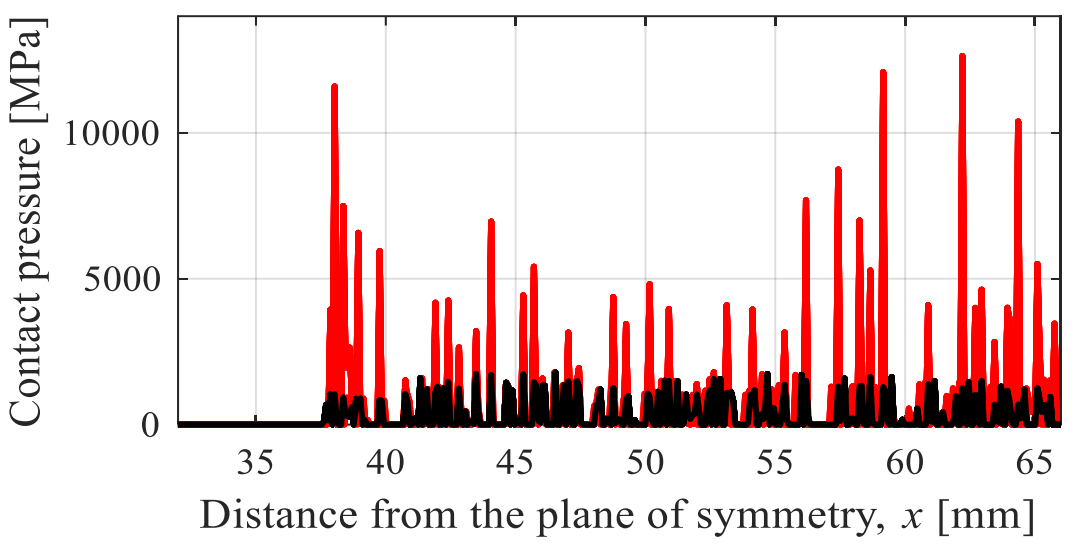

(a)

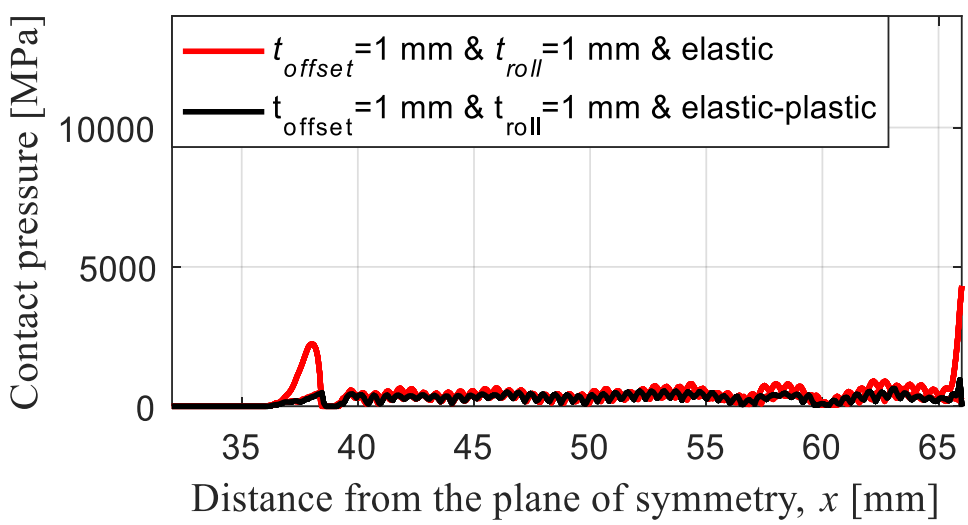

(b)

Figure 4. Contact pressure depending on an elastic or elastic-plastic behaviour of the skelp (a) between the upper roll and skelp; (b) between the bottom roll and skelp.

$$
\begin{aligned}
& \sigma=E \varepsilon_{e} \rightarrow \varepsilon_{e}=\frac{\sigma}{E} \\
& \sigma=H \varepsilon_{p}{ }^{n} \rightarrow \varepsilon_{p}=\left(\frac{\sigma}{H}\right)^{\frac{1}{n}} \\
& \varepsilon=\varepsilon_{e}+\varepsilon_{p}=\frac{\sigma}{E}+\left(\frac{\sigma}{H}\right)^{\frac{1}{n}}
\end{aligned}
$$

In the equations above, $\sigma$ is the stress, $E$ is the modulus of elasticity, $\varepsilon_{p}$ is the plastic strain, $H$ is the strength coefficient with the same units as stress, and $n$ is the strain hardening exponent and is dimensionless. 
Table 1. Yield point and ultimate point for determining the Ramberg-Osgood equation.

\begin{tabular}{|c|c|c|c|c|}
\hline & Stress, $\sigma$ & Total strain, $\varepsilon$ & Elastic strain, $\varepsilon_{\mathrm{e}}$ & Plastic strain, $\varepsilon_{\mathrm{p}}$ \\
\hline Yield point & $\sigma_{\mathrm{y}}$ & $\frac{\sigma_{y}}{E}+0.002$ & $\frac{\sigma_{y}}{E}$ & 0.002 \\
\hline Ultimate point & $\sigma_{\mathrm{u}}$ & $\frac{\sigma_{u}}{E}+\varepsilon_{f}$ & $\frac{\sigma_{u}}{E}$ & $\varepsilon_{f}$ \\
\hline
\end{tabular}

$\varepsilon=\frac{\sigma}{E}+0.002\left(\frac{\sigma}{\sigma_{y}}\right)^{\frac{1}{n}}$

$n=\frac{\log \left(\frac{\sigma_{u}}{\sigma_{y}}\right)}{\log \left(\frac{\varepsilon_{f}}{0.002}\right)}$

The $t_{\text {skelp }}$ and $t_{\text {roll }}$ were set to $1,1.5,2$ and $3 \mathrm{~mm}$ in Forming 1 and $t_{\text {offset }}$ was constant in the two-dimensional contact analysis. The $t_{\text {offset }}$ is unknown value because the contact analysis model used the roll design that has been used in the field. The detail information about the roll has not been conveyed, because much time has passed since the rolls were imported. The contact pressure on the upper surface of the skelp is generally reduced and the pressure concentration on the bottom edge of the skelp is increased as $t_{\text {skelp }}$ and $t_{\text {roll }}$ become smaller. This phenomenon anticipates the fact that the roll is designed for about $\left(t_{s k e l p}=3 \mathrm{~mm}\right.$ ) so that the gap between the edge of the skelp and the upper roll is getting wider as shown by Figure 5(a) and 5(b). Thus, it is necessary to construct a database that can classify the upper and bottom roll according to the target $t_{\text {skelp }}$ and $t_{\text {roll }}$ in the field.

Based on these facts, we performed another analysis with the upper roll differently for $\left(t_{\text {skelp }}=t_{\text {roll }}=1 \mathrm{~mm}\right)$. One case has the upper roll offset as $\left(t_{\text {offset }}=1 \mathrm{~mm}\right)$ from the bottom roll and the other case has the upper roll offset as ( $t_{\text {offset }}=2 \mathrm{~mm}$ ) from the bottom roll. In Figure 6(a) and 6(b), it can be seen that the contact pressure on the upper and the bottom surfaces of the skelp is evenly distributed in the case of $t_{\text {skelp }}=t_{\text {roll }}$ $=t_{\text {offset }}$. If the model had a finer meshes, the inhomogeneous contact pressure between the upper roll and skelp was improved. We used the reaction force on the roll as representative values to represent the contact phenomenon, because it comes from the contact pressure. The magnitude of reaction force on the upper and bottom rolls is the same, and it seems to be getting to increase dramatically as $t_{\text {skelp }}, t_{\text {roll }}$, and $t_{\text {offset }}$ are same. The magnitude of reaction force on the upper and bottom rolls was about 14,790 $\mathrm{N}$ in the case of $t_{\text {skelp }}=t_{\text {roll }}=t_{\text {offset }}$, and the magnitude of reaction force on the upper and bottom rolls was about $1,125 \mathrm{~N}$ in the case of $t_{\text {skelp }}=t_{\text {roll }} \neq t_{\text {offset }}$. 


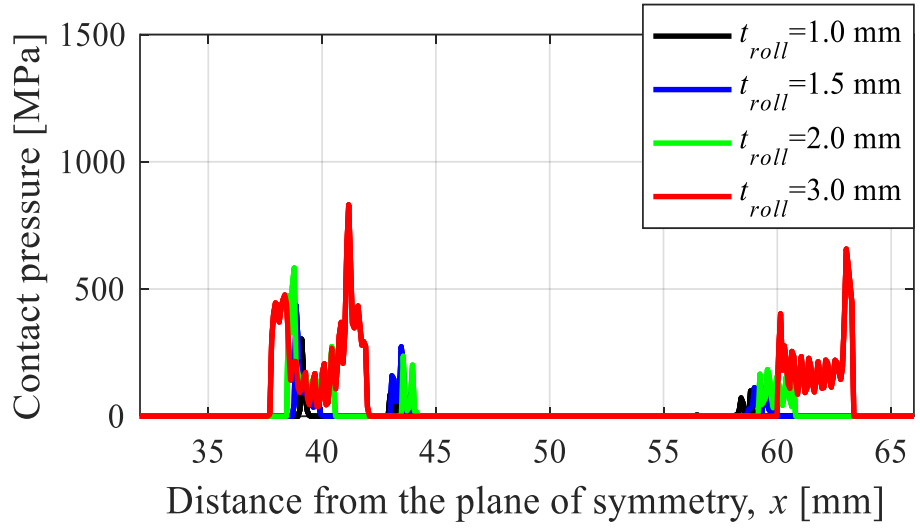

(a)

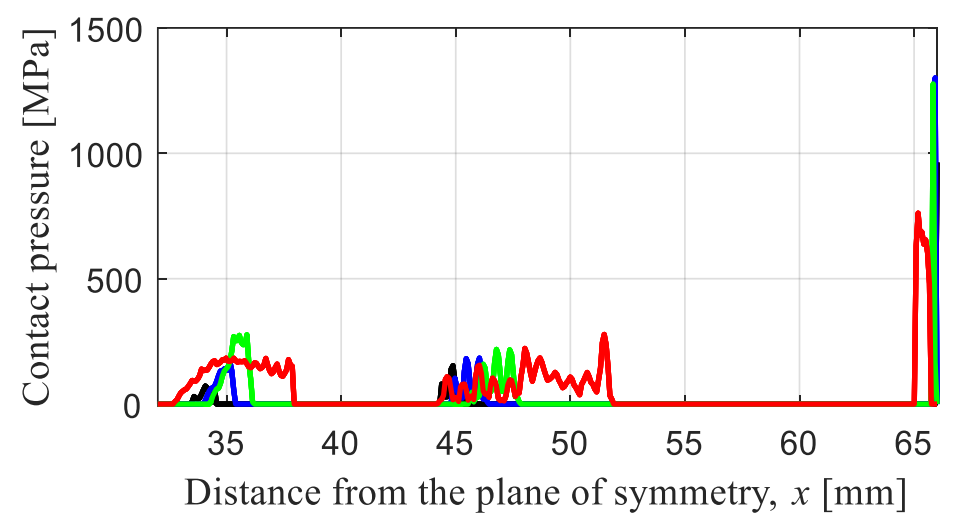

(b)

Figure 5. Contact pressure depending on $t_{\text {roll }}$ (a) between the upper roll and skelp; and (b) between the bottom roll and skelp.

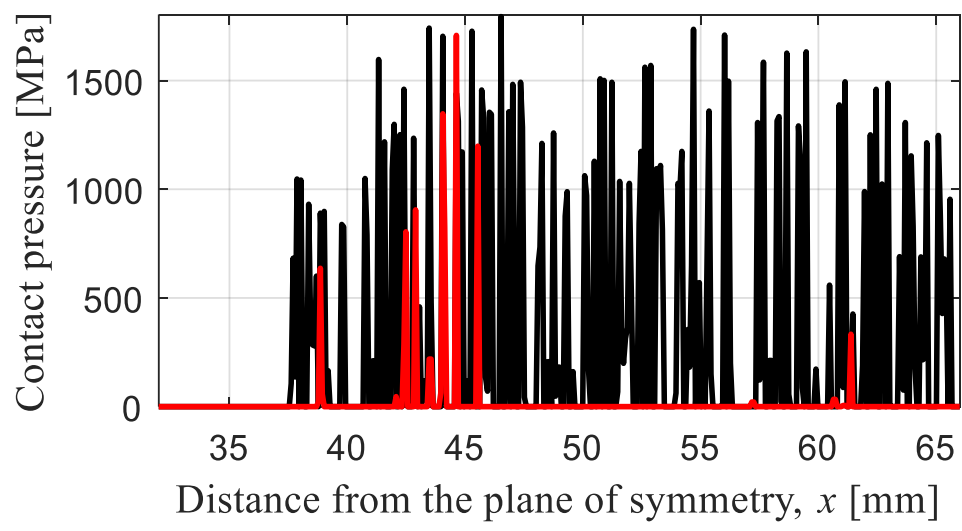

(a) 


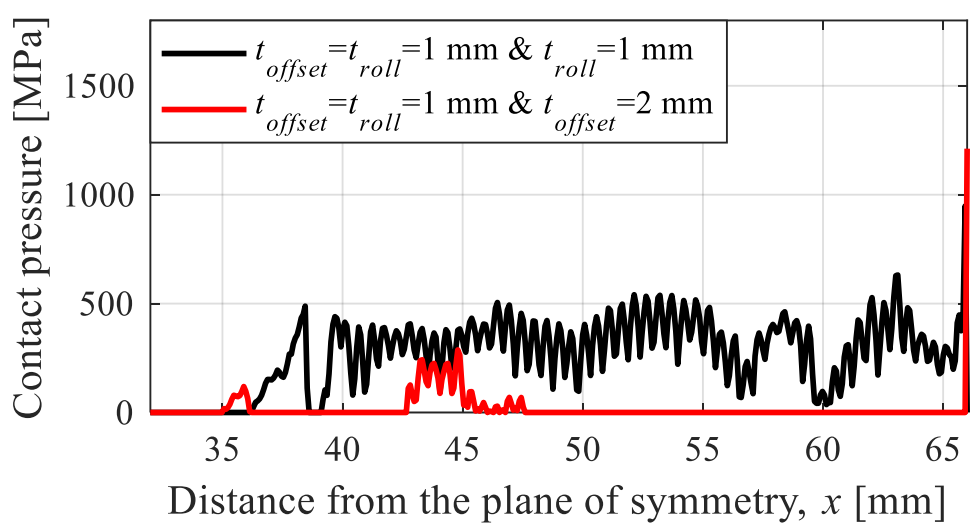

(b)

Figure 6. Contact pressure according to $t_{\text {offset }}$ and $t_{\text {roll }}$ : (a) between the upper roll and skelp; and (b) between the bottom roll and skelp.

\section{Contact Phenomenon According to the Material Property of the Skelp}

When a different material is applied to roll forming lines, it is still a big task to judge whether this change is acceptable or not in the field. Especially, it has been essential to establish a model to predict the formability and the strength of the pipes, as the high strength pipes with decreasing the thickness and the diameter, have been needed in various industries. In general, API 5L pipes are classified into X52, X56, X60, X65, X70 and X80 grades. The higher the number, the higher the yield strength and tensile strength. In this section, when different steel of the API 5L X52, X56, X60, X65, X70, and X80 are applied in the analysis under the condition that $t_{\text {skelp }}=t_{\text {roll }}=1 \mathrm{~mm}$ by the upper roll offset by $t_{\text {offset }}=1 \mathrm{~mm}$ as shown by Figure 7(a) and 7(b).

The contact pressure increases in high grade, but there is no significant change of the contact pressure on the upper surface and the bottom surface of the skelp. The contact pressure on the upper surface of the skelp in case of the API 5L X80 was raised by a those of the API 5L X52 of about one point five times. This indicates that the roll forming process of various pipes is possible regardless of the steel grade if only the vertical allowable load of the roll is acceptable. However, the contact pressure will be concentrated on the specific region and be increased dramatically when the upper and bottom rolls have elastic-plastic deformation. And $t_{\text {roll }}$ and $t_{\text {skelp }}$ are not actually same in the field, we need to conduct future works such as misalignment and machining tolerance of the roll to study the realistic distribution of the contact pressure before detail design. 


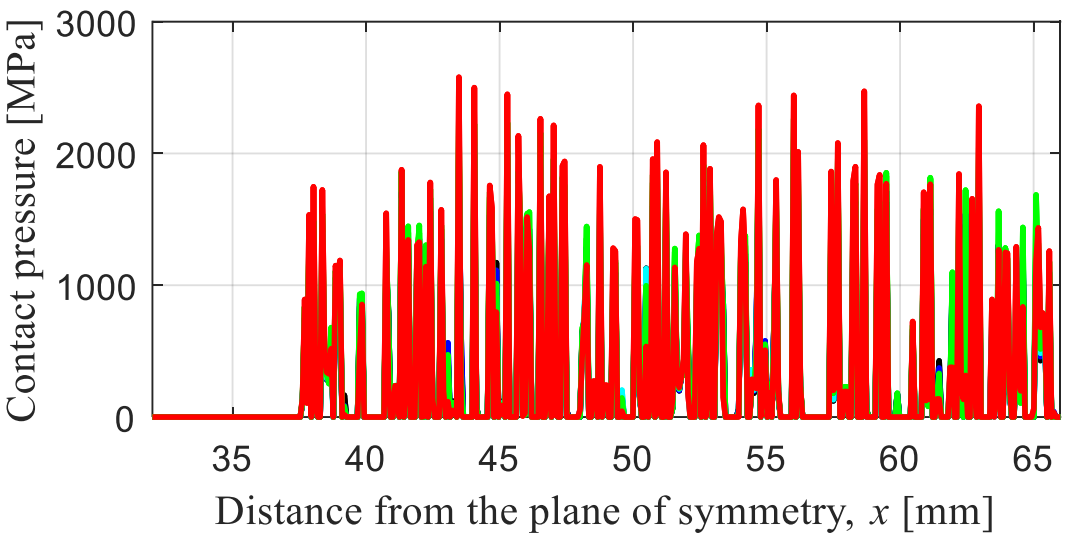

(a)

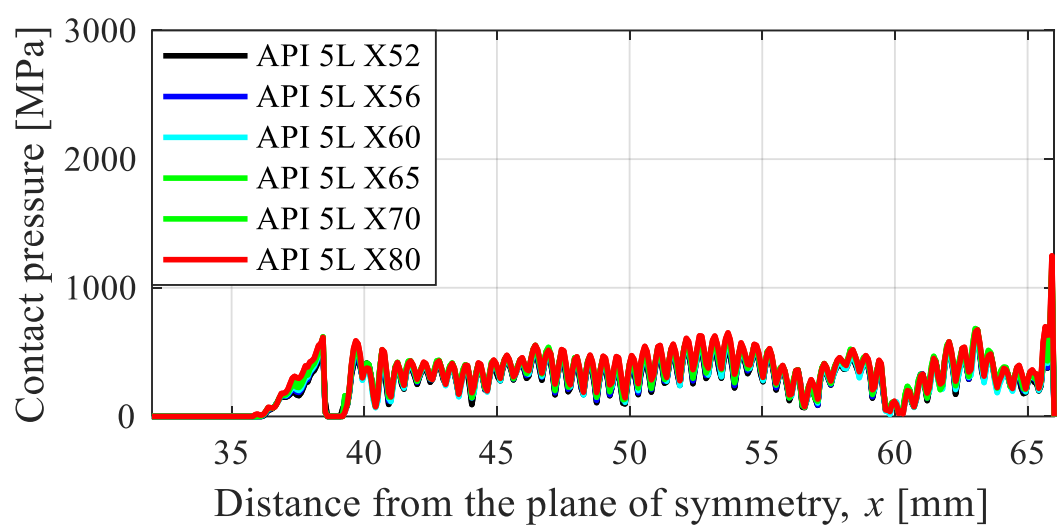

(b)

Figure 7. Contact pressure with different API 5L grade (a) between the upper roll and skelp; and (b) between the bottom roll and skelp.

\section{PARAMETRIC ANALYSIS}

\section{Three-Dimensional Analysis Model}

In this part, a three-dimensional model simulating the roll forming process was established based on the previous preliminary study of the roll design and operating conditions from the field, and parametric analysis was performed as in Figure 8 . The edge waves were studied by changing the design of the roll and skelp, and the operating condition to minimize the edge waves, and this method was checked when different material is applied. The process has four forming stages, three finpass stages, and several side roll stages such as the FOI and FPI, and the modelling and operating conditions were referred from the previous study. All rolls have rigid body motions were applied and rotate contact angular velocity except side rolls such as the FOI and FPI. To simulate the elastoplastic deformation of the skelp, the skelp has hexahedron element, and the element length in the width direction ( $y$-direction) and longitudinal direction ( $x$-direction) were maintained at 1:4 ratio based on the element length in the thickness direction ( $z$-direction). For instance, we divided the skelp into five elements in the thickness direction to see the edge waves in detail. The number of other elements is divided by the ratio. This model did not consider the heat transfer problem. Sparse method for the solver and Newton-Raphson method for the iteration were applied. 
About contact between the rolls and skelp, shear friction with friction coefficient 0.12 and separable condition after the contact, were selected.

In particular, parametric analysis of the model regarding the roll design and position was focused on minimizing the edge waves. Even though design variables and operating conditions were only changed in the Forming 1, the whole process was simulated to see whether the process can be improved by changing one part of the whole process. In Eq. (6), the plastic effective strain (equivalent strain), $\bar{\varepsilon}_{p}$, which is a value that converts the strain in the multi-axis stress state to a value corresponding to the oneaxis stress state, was selected to compare the plastic deformation with each stage easily.

$\bar{\varepsilon}_{p}=\frac{\sqrt{2}}{3}\left[\left(\varepsilon_{p, x x}-\varepsilon_{p, y y}\right)^{2}+\left(\varepsilon_{p, y y}-\varepsilon_{p, z z}\right)^{2}+\left(\varepsilon_{p, z z}-\varepsilon_{p, x x}\right)^{2}+6\left(\varepsilon_{p, x y}{ }^{2}+\varepsilon_{p, y z}{ }^{2}+\right.\right.$
$\left.\left.\varepsilon_{p, z x}{ }^{2}\right)\right]^{\frac{1}{2}}$

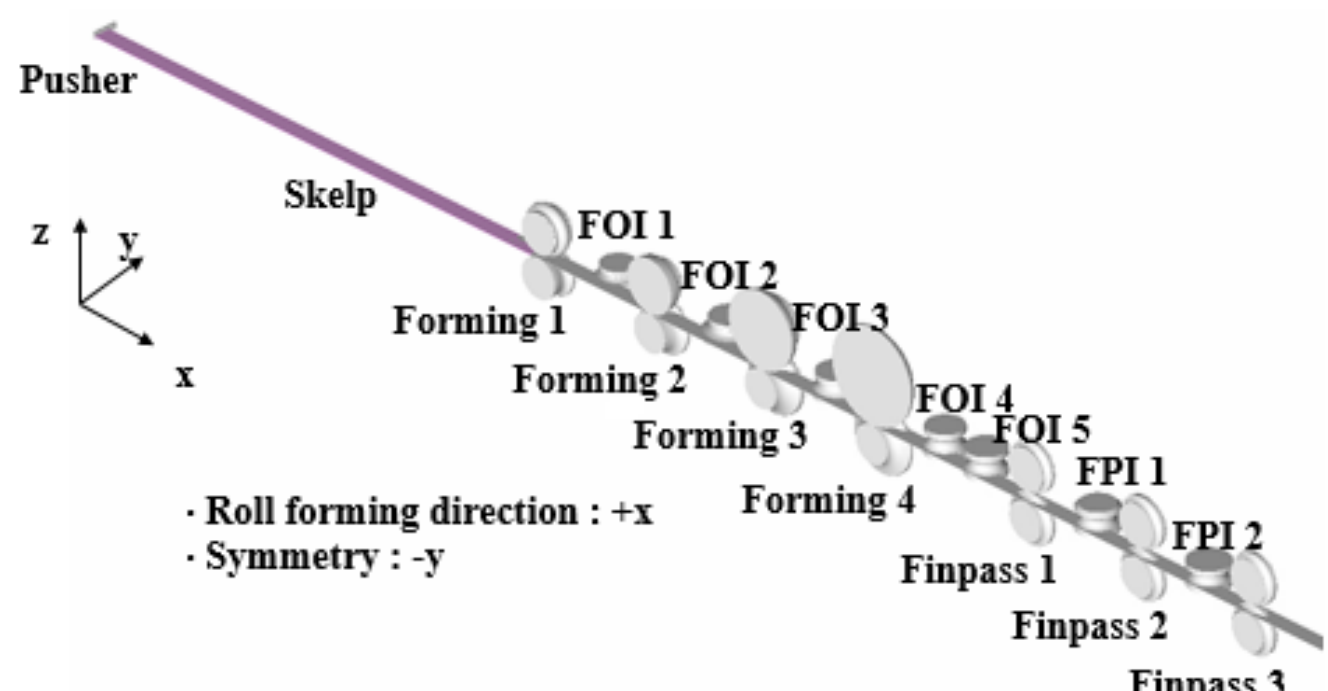

Figure 8. A three-dimensional model of roll forming process.

\section{Edge Waves According to the Position of Upper Roll of Forming 1}

Through previous work about contact phenomenon according to the roll shape, the contact pressure is concentrated on the edge of the skelp and the bottom roll, and the upper roll does not contact the edge of the skelp due to $\left(t_{\text {skelp }}=t_{\text {roll }} \neq t_{\text {offset }}\right)$. To solve the problem of not reaching the edge of the skelp to the upper roll, one method is moving the upper roll of Forming 1 about the y-direction intuitionally. Because forming roll can be divided into several parts and another part can be inserted into the several parts, unlike rolling roll.

According to this mechanism, we simulated a situation in which the upper roll of the Forming 1 was divided into two parts equally about the y-axis, and they were moved as much as $y_{\text {move }}$ in both widthwise directions. When $t_{\text {skelp }}=t_{\text {roll }}=1 \mathrm{~mm}$ and the roll is not changed, it was examined whether pipe can be produced in case of $\left(y_{\text {move }}=0\right),\left(y_{\text {move }}\right.$ $=0.2 \mathrm{~mm})$, and $\left(y_{\text {move }}=0.4 \mathrm{~mm}\right)($ Figure 9$)$. 


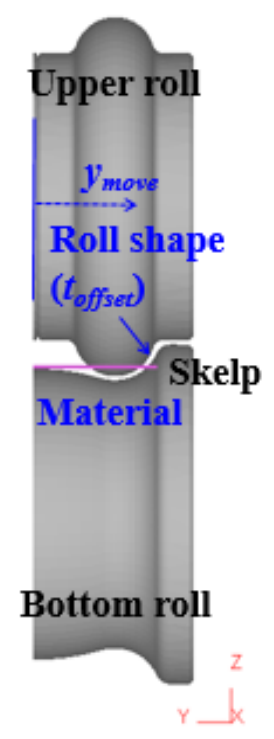

Figure 9. Variables in parametric analysis.

\section{Edge Waves According to the Design of Upper Roll of Forming 1}

When the thin pipe is difficult to be produced without the roll change, it is necessary to examine whether it is possible to proceed with the roll forming process by replacing some rolls and by remaining the other rolls to minimize trial and error and investment. Therefore, in this section, the upper was derived by offsetting as $t_{\text {offset }}$ from the surface of the bottom roll in the Forming 1 to check how the upper roll change affects the deformation of the skelp when $t_{\text {skelp }}=t_{\text {roll }}=1 \mathrm{~mm}$ (Figure 9). This offset is the same as the previous section of roll design (Figure 2). The simulation has two cases, the one has no change of the upper roll and the other one has the upper roll that was defined by offsetting $\left(t_{\text {offset }}=1 \mathrm{~mm}\right)$ from the bottom roll. No change means that the roll that was anticipated to be designed for $\left(t_{\text {offset }}=t_{\text {skelp }}=3 \mathrm{~mm}\right)$ in the previous section of contact phenomenon according to the roll shape, was applied in the simulation (Figure 5).

\section{Formability According to Material Property of Skelp}

In the previous section about the preliminary study of the roll of the Forming 1, based on the fact that the contact force is slightly increased when the material property of the skelp is higher than API 5L X52 steel, three-dimensional roll forming analysis was executed with the API 5L X52, X60, X100 respectively. In particular, we discussed the possibility of creating a new product by examining the vertical load distribution of the upper and bottom rolls and the occurrence of the edge waves.

\section{RESULTS AND DISCUSSION}

\section{Edge Waves According to Upper Roll Position in Forming 1}

The edge waves were compared with $y_{\text {move }}$ immediately after the Forming 1 , and the generation of the edge waves is the least when $y_{\text {move }}$ is not applied (Figure 10). Unlike the expectation that the edge waves will be reduced due to uniform contact between the upper roll and the edge part of the skelp when the widthwise position of the upper roll 
about the y-axis is outward, the edge waves were generated extremely. Based on the fact that the skelp slips on the surface of the rolls with different linear velocities along the transverse position of the skelp, the difference was expected to be increased due to highlocal contact pressure by $y_{\text {move }}$. To see this expectation, the two-dimensional contact analysis model was simulated by applying the same conditions including $y_{\text {move }}$ (Figure 11). The coordinates were replaced from the $x-y$ coordinates to the $y-z$ coordinates, and $+y$ direction is opposite compared to the three-dimensional model. The contact pressures were concentrated at not only the edge part and but also the new positions including ( $y=$ $48.34 \mathrm{~mm}$ for $\left.y_{\text {move }}=0.4 \mathrm{~mm}\right),\left(y=46.12 \mathrm{~mm}\right.$ for $\left.y_{\text {move }}=0.2 \mathrm{~mm}\right)$, and $(y=45.21 \mathrm{~mm}$ for $\left.y_{\text {move }}=0.14 \mathrm{~mm}\right)$. Compared to $\left(y=40.51 \mathrm{~mm}\right.$ and $55.03 \mathrm{~mm}$ for $\left.y_{\text {move }}=0 \mathrm{~mm}\right)$, they have different distributions of the contact pressures with the one spot as the center. As the roll gap is lower than $t_{\text {skelp }}$, so the skelp is sandwiched among the rolls and has high contact pressure over 10,000 MPa.

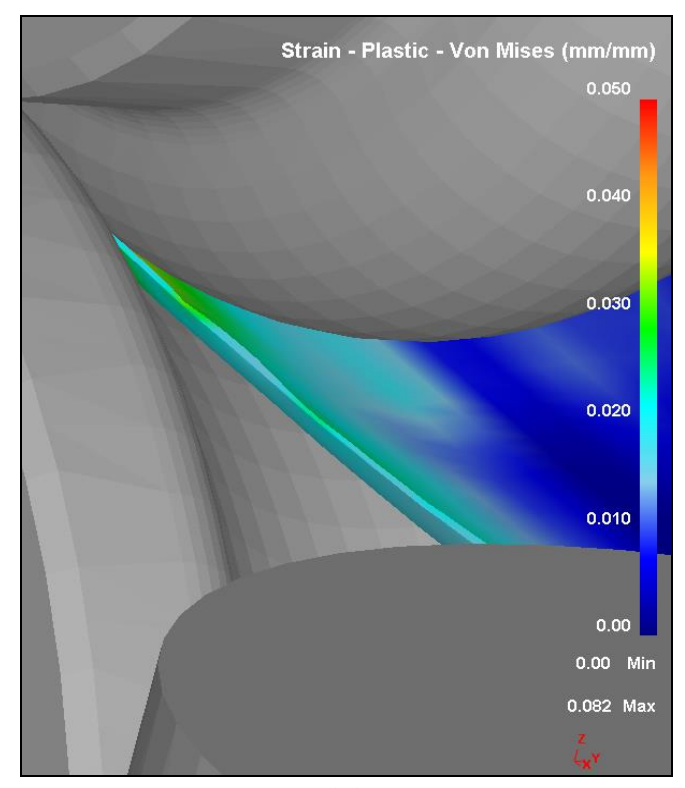

(a)

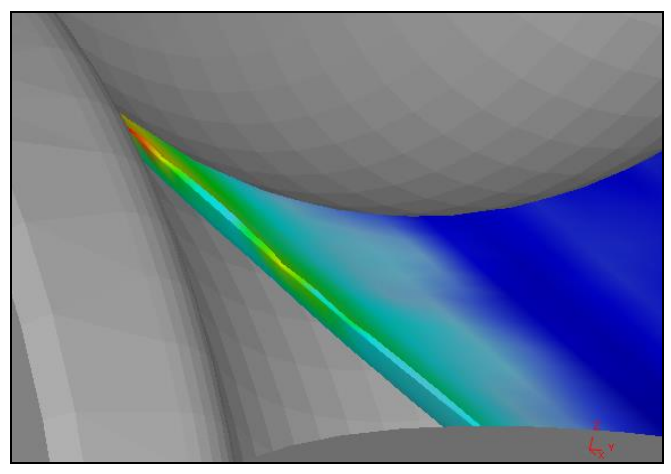

(b)

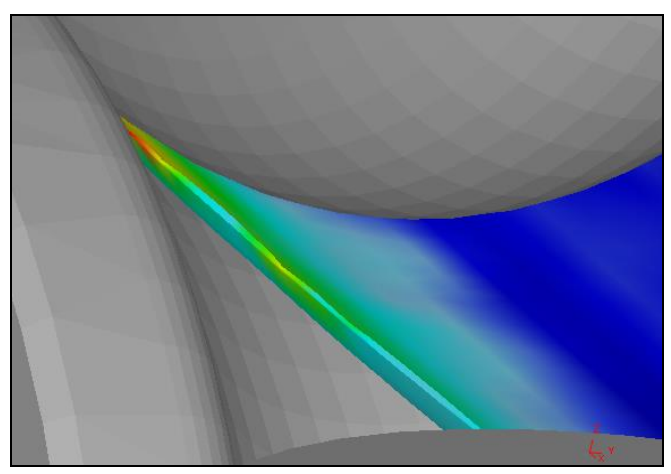

(c)

Figure 10. $\bar{\varepsilon}_{p}$ distribution depending on $y_{\text {move }}$ after the Forming 1 at (a) $y_{\text {move }}=0 \mathrm{~mm}$, (b) $y_{\text {move }}=0.2 \mathrm{~mm}$ and; (c) $y_{\text {move }}=0.4 \mathrm{~mm}$ 


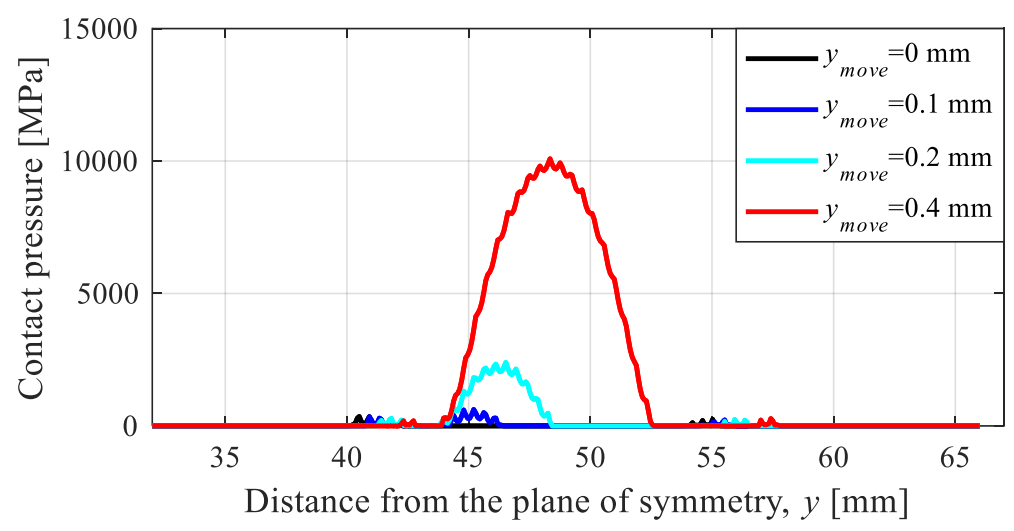

(a)

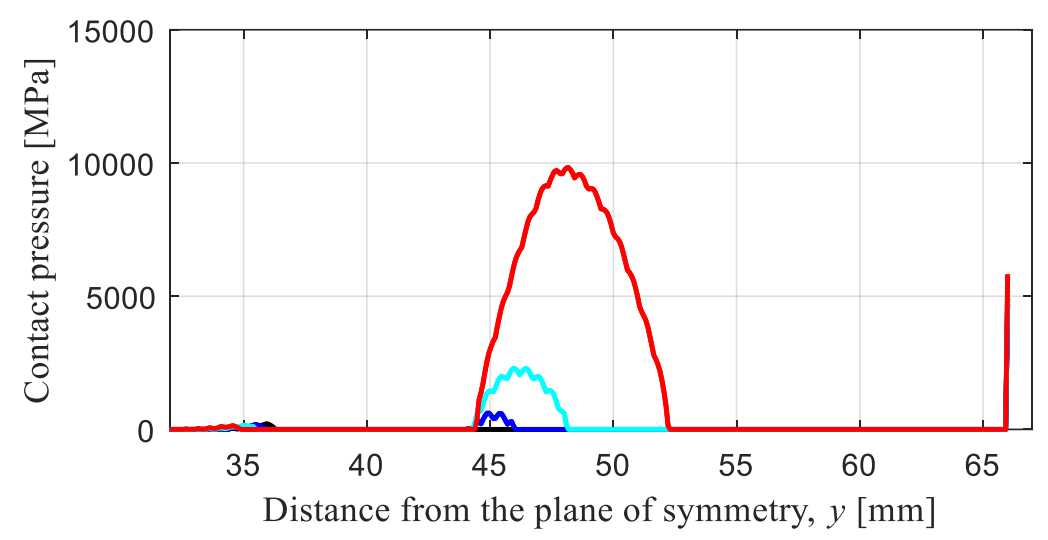

(b)

Figure 11. Contact pressure according to $y_{\text {move }}$ (a) between the upper roll and skelp; and (b) between the bottom roll and skelp.

The distribution of the contact pressure also affects the slip by changing normal forces on the skelp. The upper and bottom rolls have the same linear velocity at two spots such as $y=34.95$ and $52.12 \mathrm{~mm}$ when $t_{\text {roll }}=1 \mathrm{~mm}$ (Figure 12). If the contact pressures are well distributed around the two spots, the skelp can be formed without local distortions such as the edge waves. However, the contact pressure leans to the edge part of the skelp when $t_{\text {roll }}=1 \mathrm{~mm}$, so the edge waves always happen regardless of $y_{\text {move. }}$ In other words, the energy of the contact pressure is concentrated on the bottom edge of the skelp locally. Moreover, the edge part of the skelp was squeezed, because the rolls and skelp contact each other strongly at the unnecessary point with different linear velocity. This problem is not effective when $t_{\text {roll }}=3 \mathrm{~mm}$, because the two spots that have the same linear velocity of the upper and bottom rolls correspond to the location of the contact pressure between the bottom rolls and skelp shown by Figure 5 and 12. This is another evidence that the rolls are designed for $t_{s k e l p}=3 \mathrm{~mm}$. Overall, it can be seen that the method of changing $y_{\text {move }}$ without changing the roll design is not effective for reducing the edge waves. 


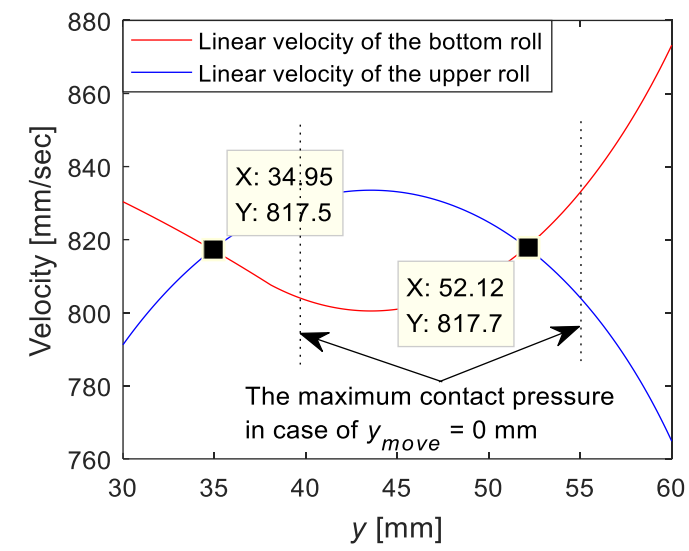

(a)

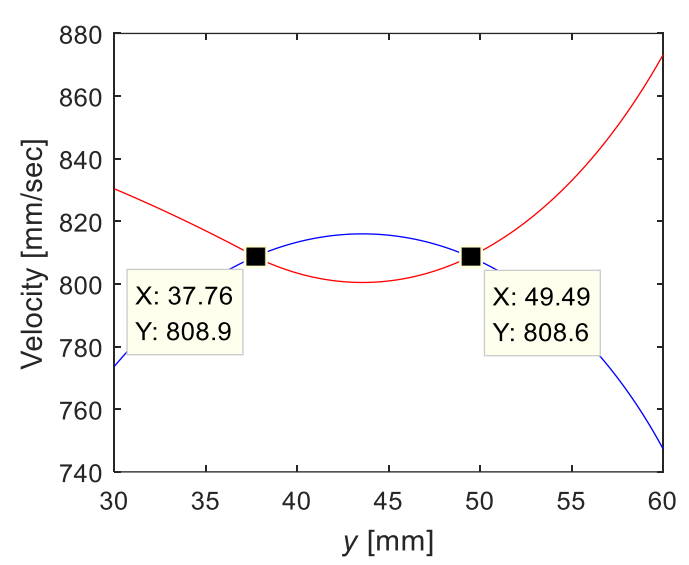

(b)

Figure 12. Linear velocity on the surface of rolls at (a) $t_{\text {roll }}=1 \mathrm{~mm}$ and; (b) $t_{\text {roll }}=3 \mathrm{~mm}$

\section{Edge Waves According to Upper Roll of Forming 1 Design}

In Figure 13, it can be seen that $\bar{\varepsilon}_{p}$ distribution is uniform at the edge part of the skelp when the upper roll that is defined by offsetting $t_{\text {offset }}=1 \mathrm{~mm}$ from the bottom roll. The facts that the contact pressure should be divided at two spots and the two spots have the same linear velocity of the upper and bottom rolls from previous two-dimensional contact analysis, were also verified. Additionally, the edge waves cannot be removed irrespective of the forming stage 2, Forming 2, because the plastic deformations are accumulated (Figure 14). Therefore, it is recommended that the analysis and design of the rolls should be conducted in order from Forming 1.

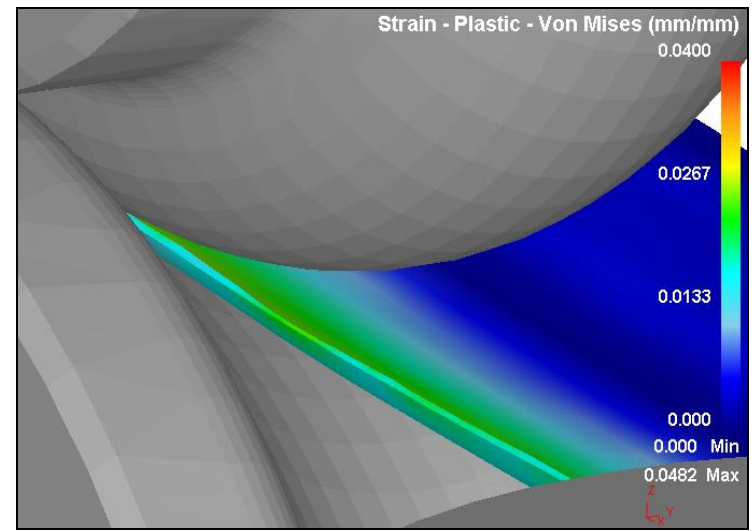

(a)

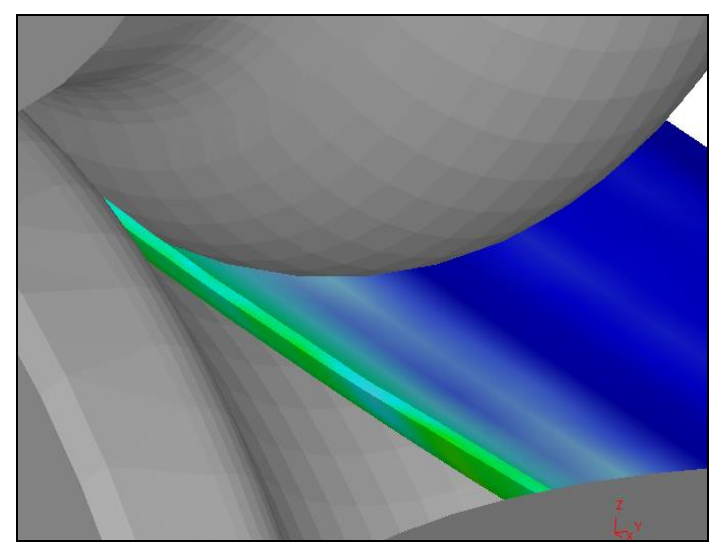

(b)

Figure 13. $\bar{\varepsilon}_{p}$ distribution depending on the upper roll 1 after Forming 1 with (a) upper roll used in the field; (b) upper roll offset, $t_{\text {offset }}=1 \mathrm{~mm}$ from the bottom roll. 


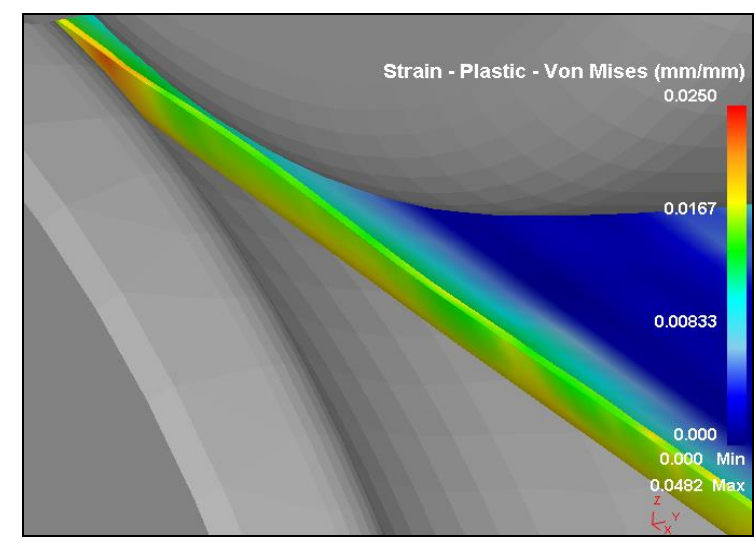

(a)

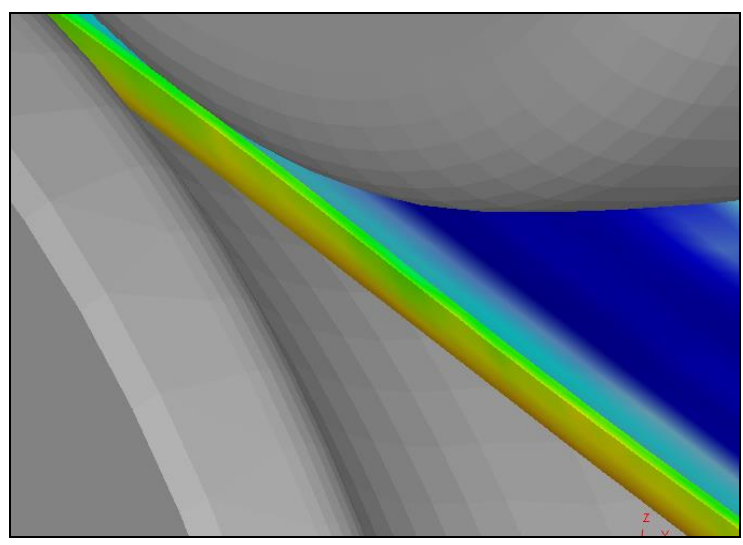

(b)

Figure 14. $\bar{\varepsilon}_{p}$ distribution depending on the upper roll after Forming 2 with (a) upper roll used in the field and; (b) upper roll offset, $t_{\text {offset }}=1 \mathrm{~mm}$ from bottom roll.

\section{Formability According to Material Property of Skelp}

No defects such as the edge waves were found after the Forming 1, when the upper roll was offset with $t_{\text {offest }}=1 \mathrm{~mm}$ from the bottom roll regardless of the material property of the skelp including API 5L X52, X60, and X100 (Figure 15). This is because the roll is assumed to be a rigid body when defining the three-dimensional model, so, the allowable load of the roll in the vertical direction about the $z$-axis is meaningless. However, it is quite important to set the allowable load in real, because roll and bearing deform according to the load. We can see that the load applied to the upper and bottom rolls is increased, as the high strength steel material is applied.

Based on the average vertical load onto the upper and bottoms rolls with API 5L $\mathrm{X} 52$, the load of the upper roll bottom roll was increased by 1.12 and 1.21 times respectively in the case of API 5L X100 (Figure 16). Therefore, it is necessary to secure a sufficient roll capacity based on the prediction of the vertical load in advance when the high strength steel is input in the existing roll forming process.

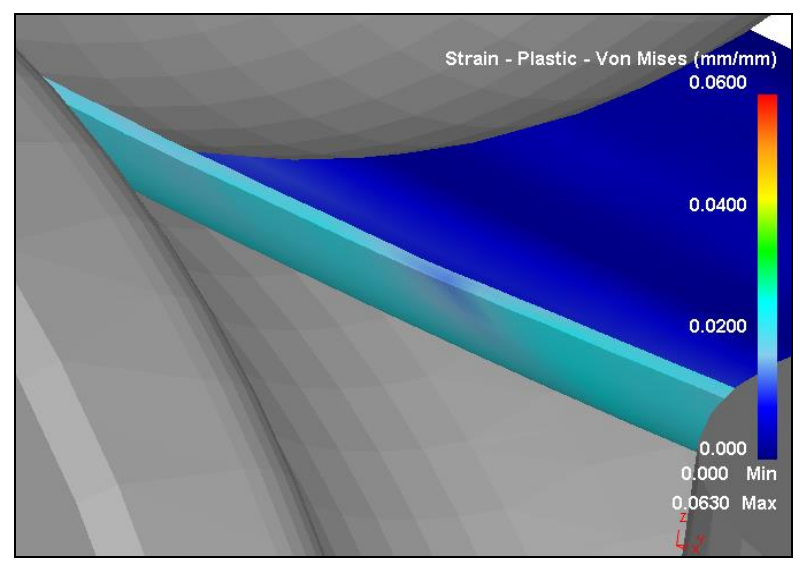

(a) 


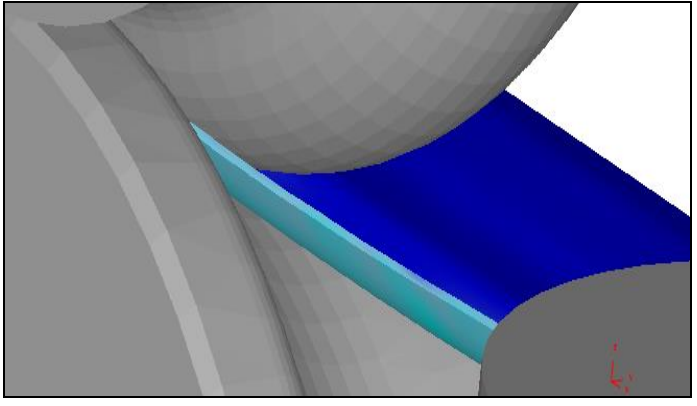

(b)

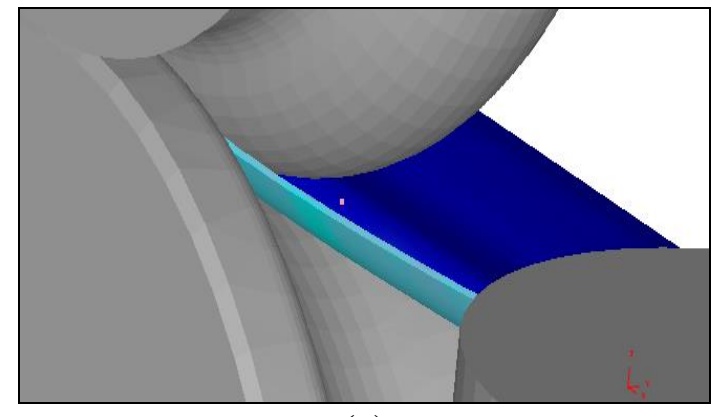

(c)

Figure 15. $\bar{\varepsilon}_{p}$ distribution depends on material property of skelp after Forming 1 for (a) API 5L X52; (b) API 5L X60 and; (c) API 5L X100.

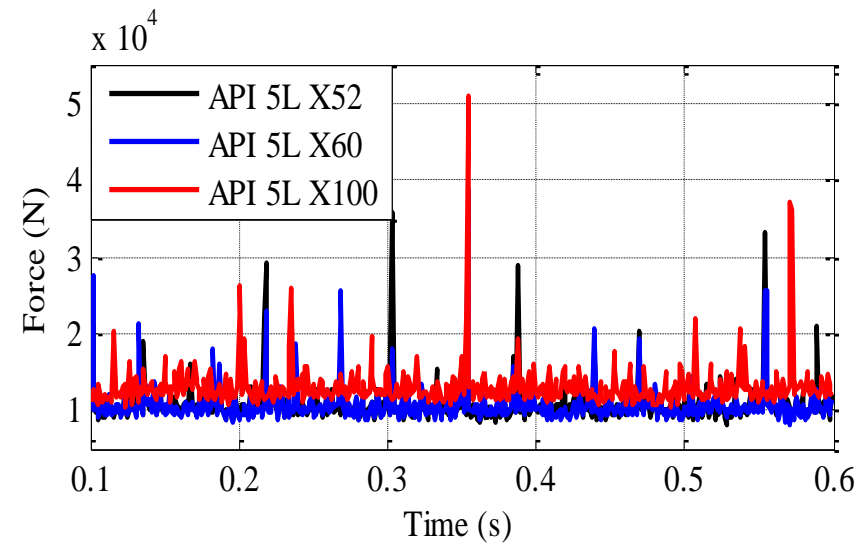

Figure 16. Vertical load distributions according to material property.

In the comparison of the formability of the pipe between the API 5L X56 and the API 5L X100, the edge waves are not found after Forming 1, and two results show similar formability of the pipe as shown in Figure 17. As described in the previous research, high $\bar{\varepsilon}_{p}$ occurred due to direct contact between the upper roll and the edge surface of the skelp while passing through the finpass stages. Especially, $\bar{\varepsilon}_{p}$ on the edge part of the skelp is increased and is decreased repeatedly between the forming stage 4 and the FOI stage 4 due to the compressive force of the $\mathrm{x}$-direction. Even though the diameter of FOI stage 4 is not designed to be smaller than the diameter pipe, the skelp has sparing back effect after the forming stages. The elastic deformation of the skelp want to return its original shape, so there is contact between the FOI and skelp. The compressive force is caused by the side roll of the FOI stage 4, since the side roll is rotated in the idle state through the contact, not like the forming and finpass stages. To make rotational torque to withstand the rotational inertia of the side roll of the FOI stage 4 , the skelp is naturally subjected to the compressive force in the longitudinal direction. Therefore, it is necessary to derive the optimum linear velocity to remove repetitive $\bar{\varepsilon}_{p}$ on the edge part of the skelp by applying a motor capable of rotating the side roll of the FOI stage 4 as well as the roll design of the Forming 1 in the case of high-strength steel material. 


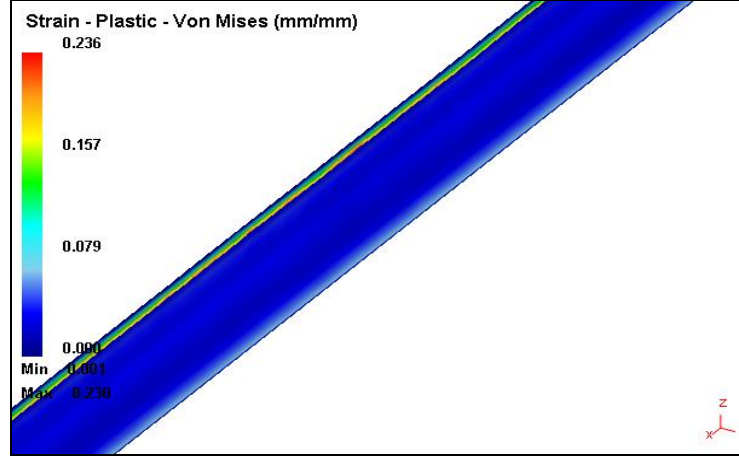

(a) API 5L X60

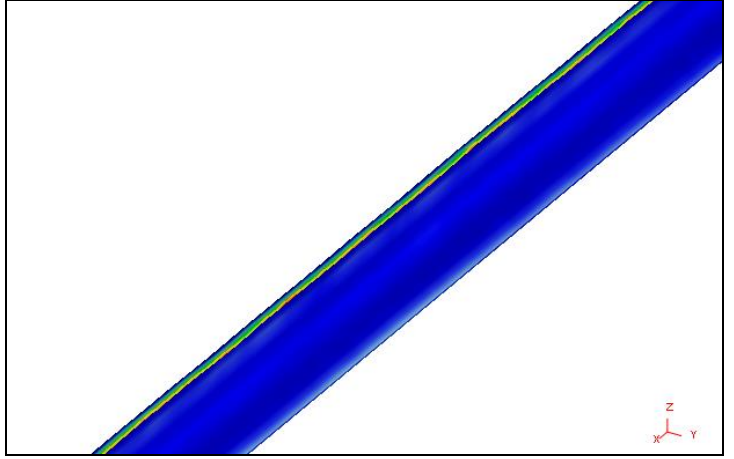

(b) API 5L X100

Figure 17. $\bar{\varepsilon}_{p}$ distribution depending on the properties of skelp at the end of process.

\section{CONCLUSION}

We have developed a method to minimize the edge waves generated by changing the operating conditions with the existing roll forming line of producing high strength thin steel pipe. To investigate the generation of the edge waves, the parametric analysis was performed in the three-dimensional model according to the roll design and the material property based on the preliminary study of the design philosophy of the roll in the twodimensional plane-strain model. It is confirmed that adjusting $y_{\text {move }}$ of the upper roll without changing the roll design has the problem of generating the edge wave and other defects when $t_{\text {skelp }}$ and $t_{\text {roll }}$ are changed arbitrarily to produce a thinner and high strength pipe.

By applying the upper roll offset by $t_{\text {offset }}$ from the bottom roll, the edge waves can be dramatically reduced. In the field, it is recommended that the range of allowable $t_{\text {skelp }}$ and $t_{\text {roll }}$ should be studied each $t_{\text {offset }}$ roll design to prevent the edge waves. We also confirmed the possibility of producing a variety of pipe products of a different material property of the skelp, if only the allowable roll capacity including the vertical direction (z) load is secured. But, this consideration need be improved by including the machine behavior. In the future, we plan to minimize the edge buckling by minimizing sudden deformation of the curvature of the pipe and extensive-compressive load onto the longitudinal direction of the skelp between the forming stage 4 and the finpass stage 1 , and to investigate validity of the roll forming process with high strength material by comparing numerical and experimental approaches.

\section{ACKNOWLEDGEMENT}

The authors thank Pohang Institute of Metal Industry Advancement and Department of Mechanical engineering, POSTECH, Pohang for their laboratory facilities, including Finite Element Analysis (FEA) software.

\section{REFERENCES}

[1] Yoder CM. Cold Roll Forming and Bending. Iron and Steel Engineer 1937; 14(2): 13-18. 
[2] Galakhar AS, Daniel WJ, Meehan PA. Review of Contact and Dynamic Phenomena in Cold Roll Forming, ARC Linkage Project Technical Paper: LP0560270; 2006.

[3] Kato K. A Basic Study on Cold Forming Technique. Nippon Kokan Kubushi Kaisha Technical Report Overseas 1963; 44-54.

[4] Suzuki H, Kiuchi M, Nakajima S, Ichidayama M. Experimental investigation on cold-roll-forming process II: distribution of contact pressure on interface between sheet metal and forming rolls in roll-forming process through tandem mills. Tokyo: University of Tokyo; 1978.

[5] Suzuki H. Investigation into Deformation Behaviours of Sheets in Cold Roll Forming Process of Wide Profile with Trapezoidal Grooves-Experimental Study on Cold Roll Forming of Wide Profiles V. Journal of the Japan Society for Technology of Plasticity 1977; 18(196): 365-372.

[6] Rhodes A, Munro T, Boardman AS. Computer-aided design and manufacture of rolls for cold roll forming machines. In: Sixteenth International Machine Tool Design and Research Conference, London, United Kingdom, pp. 251-259; 1976.

[7] Brunet M, Ronel S. Finite element analysis of roll-forming of thin sheet metal. Journal of materials processing technology 1994; 45(1-4): 255-260.

[8] Sheikh MA, Palavilayil RR. An assessment of finite element software for application to the roll-forming process. Journal of materials processing technology 2006; 180(1-3): 221-232.

[9] Park HS, Anh TV. Finite element analysis of roll forming process of aluminum automotive component. In: Strategic Technology (IFOST) International Forum on IEEE, Ulsan, South Korea, pp. 5-9; 2010.

[10] Nguyen VB, Wang CJ, Mynors DJ, English MA, Castellucci MA. Dimpling process in cold roll metal forming by finite element modelling and experimental validation. Journal of Manufacturing Processes 2014; 16(3): 363-372.

[11] Tsang KS, Ion W, Blackwell P, English M. Validation of a finite element model of the cold roll forming process on the basis of 3D geometric accuracy. Procedia Engineering 2017; 207: 1278-1283.

[12] Ghiabakloo H, Kim J, Kang BS. An efficient finite element approach for shape prediction in flexibly-reconfigurable roll forming process. International Journal of Mechanical Sciences 2018; 142: 339-358.

[13] Wang F. Numerical studies of residual stress in cold formed steel sigma sections. Birmingham: University of Birmingham; 2015.

[14] Kim N, Machida S, Kobayashi S. Ring rolling process simulation by the three dimensional finite element method. International Journal of Machine Tools and Manufacture 1990; 30(4): 569-577.

[15] Senanayake RS, Cole IM, Thiruvarudchelvan S. The application of computational and experimental techniques to metal deformation in cold roll forming. Journal of Materials Processing Technology 1994; 45(1-4): 155-160.

[16] Hong S, Lee S, Kim N. A parametric study on forming length in roll forming. Journal of Materials Processing Technology 2001; 113(1-3): 774-778.

[17] Farzin M, Tehrani MS, Shameli E. Determination of buckling limit of strain in cold roll forming by the finite element analysis. Journal of Materials Processing Technology 2002; 125: 626-632.

[18] Kim N, Kang B, Lee S. Prediction and design of edge shape of initial strip for thick tube roll forming using finite element method. Journal of Materials Processing Technology 2003; 142(2): 479-486. 
[19] Bui QV, Ponthot JP. Numerical simulation of cold roll-forming processes. Journal of Materials Processing Technology 2008; 202(1-3): 275-282.

[20] OECD. Korean Steel Market in 2017. Retrieved from https://www.oecd.org/industry/ind/Item_9_6_KOSA_Korea_Revised.pdf; 26 Sep, 2018.

[21] Tehrani MS, Hartley P, Naeini HM, Khademizadeh H. Localised edge buckling in cold roll-forming of symmetric channel section. Thin-walled structures 2006; 44(2): 184-196.

[22] Tehrani MS, Naeini HM, Hartley P, Khademizadeh H. Localized edge buckling in cold roll-forming of circular tube section. Journal of Materials Processing Technology 2006; 177(1-3): 617-620.

[23] Nepershin RI. Plane strain hot rolling of slab and strip. International Journal of Mechanical Sciences 1999; 41(11): 1401-1421.

[24] Kim YJ, Huh NS, Kim YJ, Choi YH, Yang JS. On relevant Ramberg-Osgood fit to engineering nonlinear fracture mechanics analysis. Journal of Pressure Vessel Technology 2004; 126(3): 277-283.

[25] Kamaya M. Stress-strain curve estimation procedures for stainless steels based on yield and ultimate strengths. Engineering Fracture Mechanics 2014; 127: 194-210.

[26] Kamaya M. Ramberg-Osgood type stress-strain curve estimation using yield and ultimate strengths for failure assessments. International Journal of Pressure Vessels and Piping 2016; 137: 1-12.

[27] Gere JM, Timoshenko SP. Mechanics of Materials. 2nd Edition. Monterey: Brooks/Cole Engineering Division; 1984. 